\title{
Análise da Responsabilidade Civil Médica por "Erro" à luz das decisões do Tribunal de Justiça do Acre e suas implicações na Educação Médica
}

\author{
Analysis of Medical Responsibility for Error in the light of Acre Court rulings and their \\ implications for Medical Education
}

\begin{abstract}
Análisis de la responsabilidad médica por errores a la luz de las sentencias de Acre Court y sus implicaciones para la educación médica
\end{abstract}

Lorena Carlesso Vicensi de Assunção ${ }^{1 *}$, Daniel Carlos Neto², Fernando Ambros Ribeiro².

\section{RESUMO}

Objetivo: Analisar e identificar os principais fundamentos que levaram pacientes à busca pelo poder judiciário, assim como às principais especialidades envolvidas, qualificando os critérios utilizados pelos magistrados na prolação de suas decisões. Por fim, discutir o impacto da ampliação dos conhecimentos sobre erro médico na educação. Métodos: Estudo descritivo, de análise transversal qualiquantitativo com fulcro na análise das decisões em Recursos de Apelação, por intermédio da revisão jurisprudencial do Tribunal de Justiça do Estado do Acre (TJAC) no período entre 01/01/2009 a 31/08/2018. Resultados: Analisou-se 47 decisões, com destaque para algumas especialidades, quais sejam, em ordem decrescente a Obstetrícia, Ortopedia e a Ginecologia. A Negligência (78,7\%) ficou em evidência como principal causa de pedir. Apurou-se que nas demandas em que se realizou Perícia, 58,3\% foram sentenciadas improcedentes e naquelas sem realização de Prova Pericial, 65,7\% foram consideradas procedentes.Conclusão: Evidencia-se que a origem da responsabilidade médica é na maioria das vezes a negligência. Ademais, a causa principal está ligada às questões bioéticas e suas áreas congêneres, o que demonstra a necessidade premente de readequação das normas curriculares na formação do profissional médico, com destaque para valores morais e éticos.

Palavras-chave: Erro Médico, Educação Médica, Responsabilidade Civil.

\section{ABSTRACT}

Objective: To analyze and identify the main reasons that led patients to seek the judiciary, as well as the main specialties involved, qualifying the criteria used by judges to make their decisions. Finally, discuss the impact of increased knowledge on medical error in education. Methods: cross-sectional, descriptive, qualitative and quantitative study, focusing on the analysis of decisions on appeals, through the jurisprudential review of the Acre State Court (TJAC) from 01/01/2009 to 08/31/2018. Results: We analyzed 47 decisions, highlighting some specialties, which are, in descending order, Obstetrics, Orthopedics and Gynecology. Negligence (78.7\%) stood out as the leading cause of questions. It was found that $58.3 \%$ of the claims in which Expertise was performed were unfounded and in those without expert evidence, $65.7 \%$ were confirmed. Conclusion: It is clear that the origin of medical liability is mainly negligence. In addition, the main cause is linked to bioethical issues and related areas, which demonstrates the urgent need to readjust curriculum standards in the training of medical professionals, with an emphasis on moral and ethical values.

Keyword: Medical education, Medical error, Civil liability.

${ }^{1}$ Centro Universitário UNINORTE, Rio Branco - Acre. *E-mail: Iorenacarlesso@hotmail.com

${ }^{2}$ Centro Universitário Aparício Carvalho (UniFIMCA), Porto Velho - Rondônia

SUBMETIDO EM: 8/2019

ACEITO EM: 9/2019

PUBLICADO EM: 11/2019 


\section{RESUMEN}

Objetivo: Analizar e identificar las principales razones que llevaron a los pacientes a buscar el poder judicial, así como las principales especialidades involucradas, calificando los criterios utilizados por los jueces para tomar sus decisiones. Finalmente, discuta el impacto del aumento del conocimiento sobre el error médico en la educación. Métodos: Estudio transversal descriptivo, cualitativo y cuantitativo con enfoque en el análisis de decisiones en apelaciones, a través de la revisión jurisprudencial del Tribunal de Justicia del Estado de Acre (TJAC) en el período comprendido entre el 01/01/2009 al 31/08/2018. Resultados: Analizamos 47 decisiones, destacando algunas especialidades, que son, en orden descendente, Obstetricia, Ortopedia y Ginecología. La negligencia (78.7\%) se destacó como la principal causa de preguntas. Se encontró que el $58.3 \%$ de las reclamaciones en las que se celebró Expertise eran infundadas y en aquellas sin evidencia de expertos, el $65.7 \%$ fueron confirmadas. Conclusión: es evidente que el origen de la responsabilidad médica es principalmente negligencia. Además, la causa principal está vinculada a cuestiones bioéticas y sus áreas similares, lo que demuestra la necesidad urgente de reajustar las normas curriculares en la formación de profesionales médicos, con énfasis en los valores morales y éticos.

Palabras clave: Error médico, Educación médica, Responsabilidad civil.

\section{INTRODUÇÃO}

Nas duas últimas décadas, o médico tornou-se uns dos principais protagonistas no cenário jurídico brasileiro, inaugurando o fenômeno intitulado de "Judicialização da Medicina", com um crescimento exponencial de litígios, onde se questiona a Responsabilidade Civil no exercício da profissão, ultrapassando em mais de $1600 \%$ os limites documentados do início da década de 90 (SIMÕES MCR, et.al., 2018).

A Responsabilidade Civil por erro médico remonta ao período de 1686-1750 a.C, com o famigerado Código de Hammurabi, o qual penalizava os médicos que praticassem lesões ou contribuíssem para o óbito de seus pacientes. Entretanto, o marco jurídico do instituto da responsabilização por erro médico, se deu sob a influência do Direito Francês (DANTAS E, 2019).

No Brasil esse instituto esteve vinculado ao Direito Penal, como garantia de indenização à vítima em razão de um dano causado, adquirindo espaço no Direito Civil, a partir da promulgação da Constituição Federal em 1988, que prestigiou a reparação por dano moral, alcançando sua independência completa com a entrada em vigor do Código de Defesa do Consumidor em 1990 (DANTAS E, 2019).

Desde então, o instituto da responsabilidade civil médica evoluiu de maneira desordenada, impossibilitando que o Poder Judiciário se aperfeiçoasse tecnicamente para julgar essa matéria, contudo, isso não foi impedimento, mas sim, solo fértil para o ativismo judicial, terreno de anarquia e insegurança jurídica, cujo principal prejudicado é o médico que passa a ocupar posição de vulnerabilidade no exercício da profissão (NETO DC, 2018).

De outro lado, concomitantemente, engendrou-se uma política inconsequente de abertura desenfreada de escolas médicas, desprovidas de estrutura física e pedagógica mínima para formação e qualificação de médicos, resultando em egressos completamente despreparados para o exercício profissional sob o aspecto técnico e ético (LOPES AC, 2018).

O ensino da bioética e do biodireito são complementares e, portanto, indissociáveis da formação médica, compondo um modelo afeto não apenas ao conhecimento científico, mas também filosófico e sociopolítico, contemplando a integralidade do novo paradigma de atendimento sob o aspecto biopsicossocial (CARNEIRO LA, et.al., 2010).

Nesse contexto dicotômico de malformação médica, o profissional está cada vez mais vulnerável ao acometimento de situações de erro médico, seja ele de caráter técnico ou ético, com tendência ao agravamento, face à cooperação de elementares como a precarização das condições de trabalho e 
excessivas jornadas de trabalho, refletindo no atendimento ao paciente, o qual pela mudança de paradigma jurídico passa a ocupar cada vez mais a posição de consumidor, isto é, menos tolerante com quaisquer espécies de danos (KFOURI N, 2013).

Não obstante, a educação médica tem duas atribuições salutares, a primeira, fornecer instrumentos de natureza técnico-científico para o profícuo exercício da atividade profissional, a segunda, investir no ensino maciço da bioética e do biodireito, visando formar médicos aptos a compreenderem a estrutura biopsicossocial do paciente, igualmente, engajados no gerenciamento jurídico preventivo, objetivando alcançar maior grau de segurança jurídica no exercício da medicina (BITENCOURT AGV, et.al., 2007).

O objetivo do estudo foi identificar as principais causas e fundamentos que chancelam a busca de um provimento jurisdicional pelo pacientes, além de verificar quais especialidades médicas são mais demandadas, examinando os critérios invocados pelos magistrados na lavratura de suas decisões, e, por conseguinte, estabelecer um paralelo da ingerência da educação médica neste cenário.

\section{MÉTODOS}

Trata-se de um estudo descritivo, de análise transversal qualiquantitativo, com fulcro na análise das decisões em Recursos de Apelação, por intermédio da revisão jurisprudencial do Tribunal de Justiça do Estado do Acre (TJAC) no período entre 01/01/2009 a 31/08/2018, onde se utilizou para pesquisa os termos "erro médico" e "responsabilidade civil por erro médico".

A princípio elegeu-se 124 decisões, eliminando posteriormente os julgados nos quais se debatia a responsabilidade de outras profissões da área da saúde, requisições de medicamentos, processos extintos pelo instituto da prescrição, julgados anulatórios de decisões de primeiro grau, demandas que versavam sobre a prestação de serviços por parte dos planos de saúde, causas criminais, previdenciárias e por fim, ações cominatórias.

A partir da análise acurada dos arestos, selecionou-se 47 decisões, das quais se analisou as seguintes variantes: Ramo da expertise médica; Data de prolação das decisões em grau recursal; Comarca de origem dos fatos; Realização de prova pericial; Os fatos e fundamentos jurídicos do pedido; A decisão de mérito em primeira instância e os Acórdãos em Recurso de Apelação;

A verificação bibliográfica se deu na base de dados da Biblioteca Virtual da Saúde e Science Direct, com os descritores Erro médico/Mala práxis/Medical error, cujas publicações se deram a partir do ano de 2002.

Todos os dados utilização são de natureza jurídica pública e disponibilizados no sítio eletrônico do TJAC, em estrita observância do Art. 1丷, Parágrafo único, da Resolução № 510, de 07 de Abril de 2016, o qual dispensa registro e avaliação pelo sistema do Comitê de Ética em Pesquisa e Comissão Nacional de Ética em Pesquisa, sem conflito de interesses.

\section{RESULTADOS e DISCUSSÃO}

Os resultados encontrados no presente estudo revelam o atual cenário da atuação médica, em especial pelo alto índice da culpa na modalidade de negligência, com destaque para relação médico-paciente, reportando à elementares bioéticas, caracterizadas pela falta de cuidado ou precaução na execução do ato médico (CREMESP, 2019).

Derivou-se da análise das decisões um total de 124 arestos, dos quais foram incluídos 47 julgados de relevância para o estudo.

Os litígios foram fragmentados por especialidades, onde se verificou a seguinte recorrência: $32 \%$ Obstetrícia; 17\% Ortopedia; 10,6\% Ginecologia; 8,5\% Oftalmologia; 6,4\% Plantonista de Urgência/Emergência; 6,4\% Cirurgia Geral; 4,3\% Anestesiologia; 4,3\% Cardiologia; 2,1\% Cirurgia Plástica; 2,1\% Imaginologia; 2,1\% Dermatologia; 2,1\% Pediatria; 2,1\% Intensivista (Gráfico 1). 
Gráfico 1 - Recorrência das ações de responsabilidade civil por erro médico no TJAC, de acordo com a expertise.

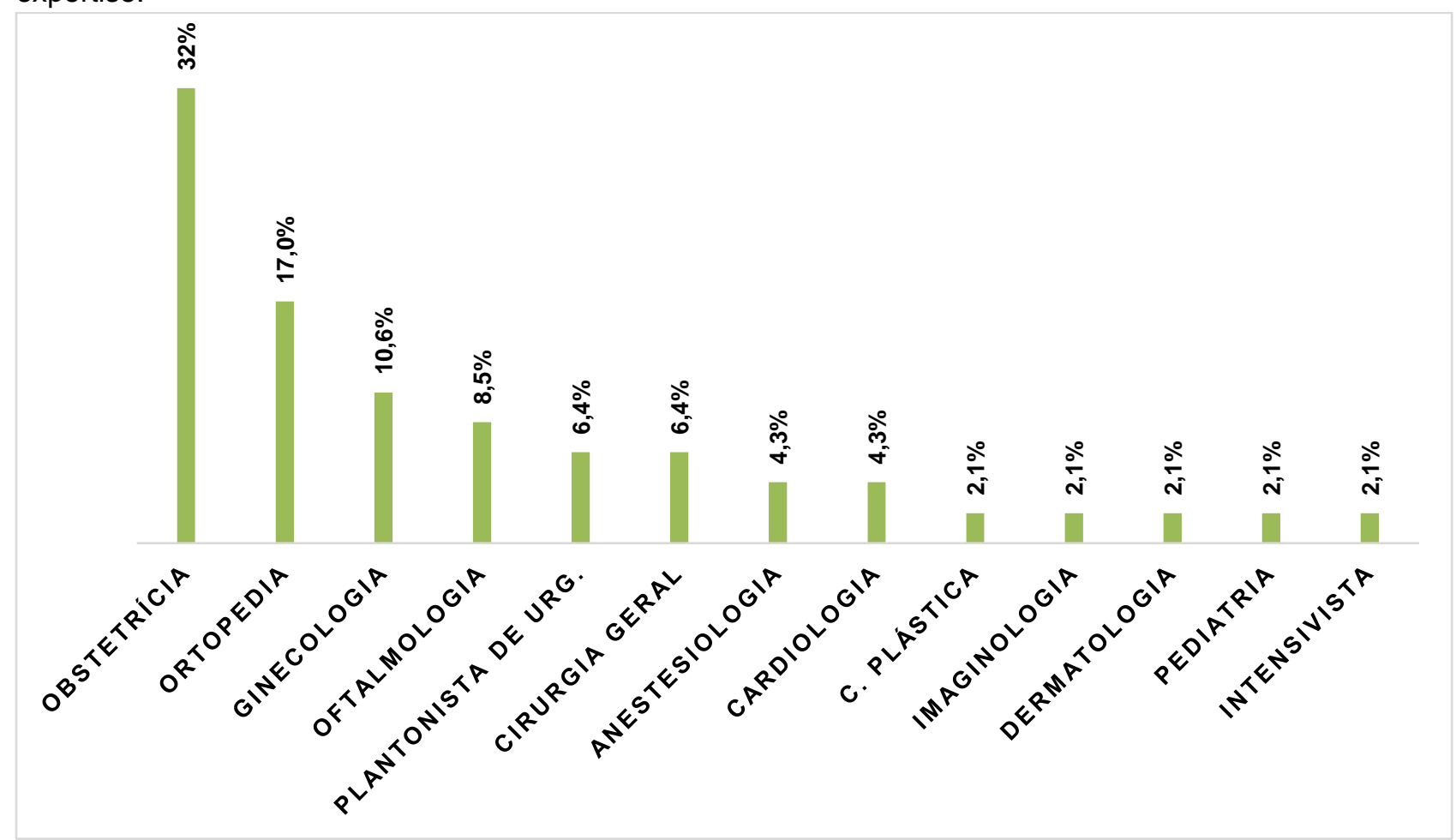

Fonte: Tribunal de Justiça do Estado do Acre, 2018.

Analisou-se nos arestos os fatos e fundamentos jurídicos do pedido, dos quais se interpelou a culpa lato sensu na seguinte proporção: 78,7\% Negligência e 4,3\% Imprudência; 4,3\% latrogenia e 12,7\% Erro de Diagnóstico (Gráfico 2).

Gráfico 2 - Tipos de infrações denunciadas.

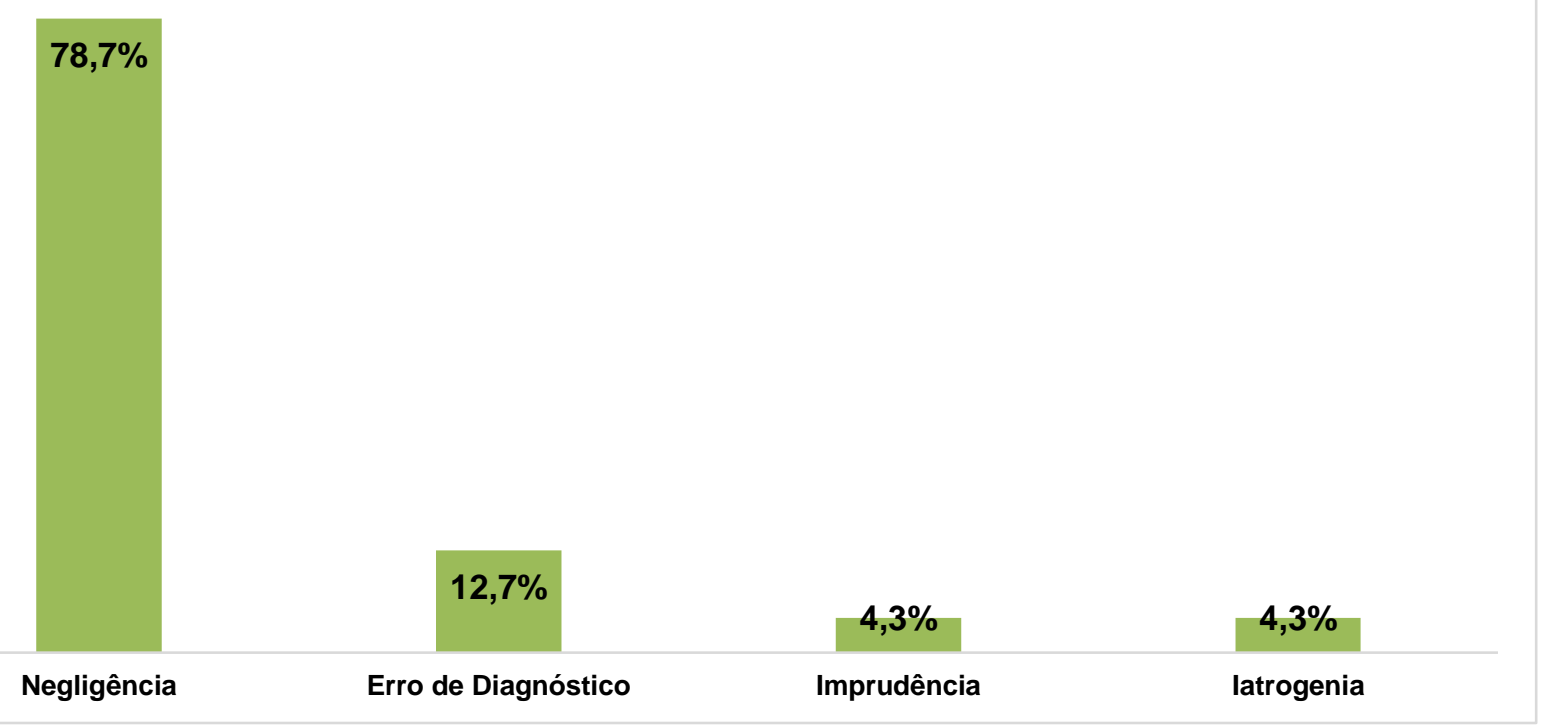

Fonte: Tribunal de Justiça do Estado do Acre, 2018. 
No tocante à distribuição por comarcas aferiu-se a seguinte proporção: 85,2\% Rio Branco; 4,3\% Brasiléia; 2,1\% Xapuri; 2,1\% Cruzeiro do Sul; 2,1\% Senador Guiomard; 2,1\% Sena Madureira e 2,1\% Capixaba.

Da análise das sentenças de primeira instância, observou-se que $63,8 \%$ foram julgadas procedentes e $36,2 \%$ improcedentes, dessas $97,9 \%$ foram confirmadas ou parcialmente reformadas no tocante ao quantum indenizatório em grau de recurso de apelação e 2,1\% foram totalmente reformadas.

No que se refere aos instrumentos probatórios, a perícia médica foi realizada em $25,5 \%$ dos casos na contramão de $74,5 \%$. Daqueles em que se utilizou a prova pericial $41,7 \%$ tiveram seu pleito julgado procedente contra 58,3\% improcedente. Em contrapartida, nas demandas em que não se utilizou 0 instrumento pericial como subsídio probatório $65,7 \%$ foram julgadas procedentes e $34,3 \%$ improcedentes (Gráfico 5).

Gráfico 5 - Relevância da Perícia Médica nos processos por Erro Médico.

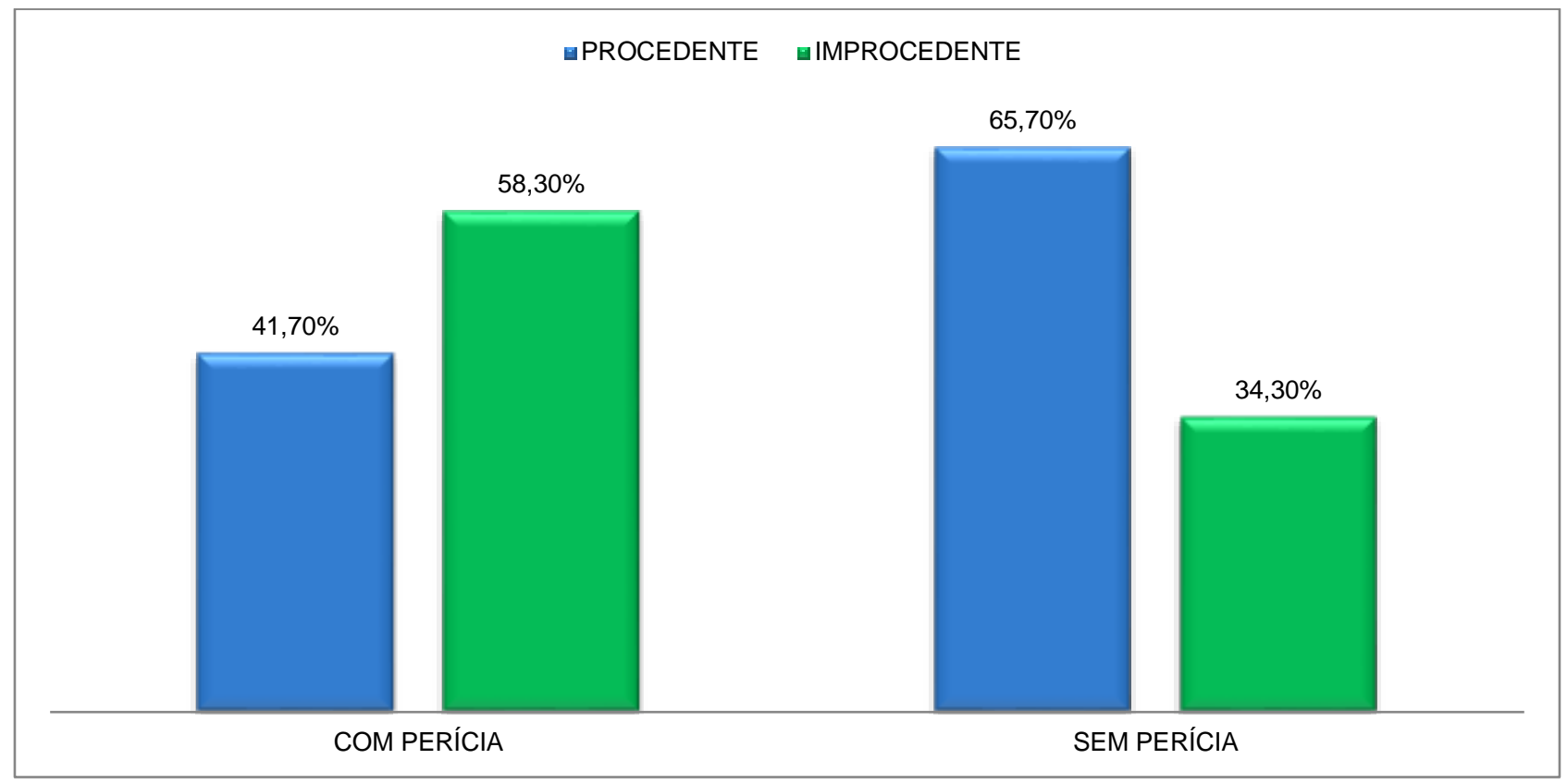

Fonte: Tribunal de Justiça do Estado do Acre, 2018.

Constata-se pelos dados levantados que $83 \%$ do famigerado erro médico fundamentam-se na culpa lato sensu, com destaque para a especialidade de obstetrícia, estatística essa que vai ao encontro de estudos realizados a nível estadual e nacional, onde se observou ser a especialidade mais demandada por condutas médicas tecnicamente questionáveis (CONJUR, 2017; NETO DC, 2019).

A negligência na atuação médica, não raras vezes é involuntária, porém evitável, dado que ela é reflexo da inércia, da displicência e da indiferença do médico, deixando de adotar as cautelas necessárias (KFOURI $\mathrm{N}, 2013)$.

Ademais, a visão holística do paciente, esteio da assistência humanizada, foi substituída pelo atendimento automatizado e hospitalocêntrico, conjuntura resultante da formação médica sem bases bioéticas, solo fértil para negligência (VALENTIM IVL, et.al., 2007).

Não se pode desprezar o fato de que a atividade médica não está isenta de infortúnios, no entanto, há de se analisar com cautela o contexto e suas elementares, para estabelecer de maneira irrefutável o nexo de causalidade entre a conduta profissional e o dano gerado. Nessa seara, a dificuldade em se atribuir ou não a culpa do dano médico está na apuração da conduta, se ela foi consequência de uma falha por carência de conhecimento técnico-científico ou de uma incorreção involuntária, permitindo que o órgão julgador possa se 
convencer da ocorrência de lesão iatrogênica, que isenta o agente de culpa, ou a presença do nexo de causalidade associado à imperícia, negligência ou imprudência (NETO DC, 2017).

É consabido que nas lides em que se questiona a culpa lato sensu, para que o magistrado possa proferir um julgamento técnico-jurídico se faz necessário conhecimentos médicos específicos, os quais o magistrado não possui, tornando salutar a prova pericial (MARINONI LG, et al. 2017), fundamento ratificado pelas estatísticas do presente estudo, o qual revelou que nos processos em que se realizou perícia médica, 58,3\% foram julgados improcedentes, na contramão dos que não se realizara a prova técnica, $65,7 \%$ foram procedentes.

Nessa perspectiva, foi possível identificar a importância do instrumento pericial como meio de prova nas demandas onde se questiona a responsabilidade civil do médico por erro, fornecendo ao magistrado expertise científica para formação do seu convencimento na determinação da ocorrência da culpa provada ou presumida (SILVA OAB, 2008).

Ademais, a prova pericial nas demandas em que se questiona o erro médico, já vem sendo considerada pelos doutrinadores e juristas da área como indispensável para o efetivo processo legal e exercício pleno da ampla defesa e do contraditório (SCAFF FC, 2010), fundamento este validado por estudos científicos que comprovam que na maioria dos processos de erro médico a realização da perícia evidenciou a inexistência de culpa ou dolo por parte do profissional médico (NETO DC, 2019).

Noutro norte, é insofismável a premente necessidade em se reconhecer o papel da educação médica na prevenção do erro médico, em virtude da deficitária formação ética e humanística, responsável pelo transtorno de conduta no exercício da profissão (BITENCOURT AGV, et.al., 2007).

É indubitável que a gênese do erro médico seja multifacetada, entretanto, a degeneração dos valores éticos na relação médico-paciente ocupa importante posição na Judicialização, conforme comprovado pelos resultados deste estudo.

Nesse mesmo sentido, alguns estudos atestam que há uma formação médica técnica, humanista e ética deficitária em ascendência, acompanhada pelo crescente e desordenado número de escolas médicas sem o mínimo de estrutura, o que tem contribuído para a degradação da relação médico-paciente e o consequente número de ações judiciais por erro médico (BITENCOURT AGV, et.al., 2007).

Para rechaçar essa realidade, é salutar que o ensino da Bioética, Ética Médica e do Biodireito, sejam ministrados ao longo de toda graduação em Medicina, promovendo a discussão de casos concretos que estimulem a reflexão e consolidem a compreensão de elementos indispensáveis na conduta profissional. (GOMES JCM, 1996).

Não obstante, há de se investir no corpo docente qualificado neste setor, não apenas com o domínio didático, mas com a experiência necessária, pois, a atuação médica antijurídica possui nuances sui generis (NETO DC, 2018).

\section{CONCLUSÃO}

O estudo demonstra uma tendência crescente da Judicialização da relação médico-paciente, em especial das especialidades cirúrgicas. Contudo, a origem da responsabilidade médica é na maioria das vezes comum, notadamente a negligência. Evidencia-se, pelos dados do presente estudo, que a causa principal do erro médico está intimamente ligada às questões bioéticas e suas áreas congêneres, o que demonstra a necessidade premente de readequação das normas curriculares na formação do profissional médico, não apenas consubstanciada na formação técnica, mas com destaque especial para valores morais e éticos.

\section{REFERÊNCIAS}

1. BITENCOURT AGV, et al. Análise do erro médico em processos ético-profissionais: implicações na educação médica. Revista Brasileira de Educação Médica, (2007); 31(3), 223-228. 
2. BRASIL. Consultor Jurídico. Obstetrícia é maior geradora de litígios na medicina, aponta pesquisa. Disponível em: < https://www.conjur.com.br/2017-mai-18/obstetricia-concentra-litigios-medicina-aponta-pesquisa>. Acesso em: 05 out. 2019

3. CARNEIRO LA, et al. O ensino da ética nos cursos de graduação da área de saúde. Revista Brasileira de Educação Médica, 2010; 34(3), 412-421.

4. CREMESP - Conselho Regional de Medicina do Estado de São Paulo. Manual de ética em ginecologia e obstetrícia. Considerações sobre a responsabilidade médica. Disponível em: https://www.cremesp.org.br/?siteAcao=Publicacoes\&acao=detalhes_capitulos\&cod_capitulo=52. Acesso em: 06 jan. 2019.

5. DANTAS E. Direito Médico. 4. ed. rev. ampl. e atual. Salvador: JusPodvum, 2019.

6. GOMES JCM. O atual ensino da ética para os profissionais de saúde e seus reflexos no cotidiano do povo brasileiro. Bioética, 1996; 4(1): 53-64.

7. KFOURI N. Responsabilidade civil por erro médico. 2. ed. São Paulo: Atlas, 2013, p. 99.

8. LOPES AC. A explosão numérica das escolas médicas brasileiras. Educación Médica (Ed. impresa) v. 19, p. 19-24, 2018.

9. MARINONI LG, et al. Novo Código de Processo Civil Comentado. $3^{\mathfrak{a}}$ ed. São Paulo: Revista dos Tribunais, 2017, p. 567 e 569.

10. NETO DC. Erro médico no Estado de Rondônia: uma realidade nacional. Revista Eletrônica Acervo Saúde, $2019 ;$ v. 11 , n. 11 , p. $268-275$

11. NETO DC. Direito Médico: À Luz da Doutrina e Jurisprudência para Médicos e Residentes. $2^{\underline{a}}$ ed. Porto Velho: Motres, 2018.

12. NETO DC. Mala praxis médica no Estado de Rondônia: uma realidade nacional. In: Proceedings abstracts 9th International Congress of Child and Adolescents Health; 2018 Nov 22-25, Rio Branco Brazil. São Paulo: Journal of Human Growth and Development; 2019. p.220.

13. NETO DC. A (Des) Medicalização na Atenção Primária: o surgimento de um novo cenário na Saúde Pública. Revista Científica Fagoc Saúde, 2017; v. 1, p. 09-14.

14. SCAFF FC. Direito à saúde no direito privado. 1ª ed. São Paulo: Saraiva, 2010. p. 106 e SS

15. SILVA OAB. Curso de Processo Civil. vol. I, 8ae ed., São Paulo: Revista dos Tribunais, 2008, p. 300 a 302.

16. SIMÕES MCR, SENA TAB. Direito Médico: À Luz da Jurisprudência para Médicos e Residentes. 1. ed. Porto Velho: Lexia, 2018.

17. VALENTIM IVL, KRUEL AJ. A importância da confiança interpessoal para a consolidação do Programa de Saúde da Família. Ciênc. Saúde Coletiva. 2007; 12(3):777-88. 